\title{
Women in post-trafficking services in moldova: diagnostic interviews over two time periods to assess returning women's mental health
}

\author{
Nicolae V Ostrovschi ${ }^{1,4}$, Martin J Prince ${ }^{2}$, Cathy Zimmerman ${ }^{5}$, Mihai A Hotineanu ${ }^{1,4}$, Lilia T Gorceag ${ }^{3}$,
} Viorel I Gorceag ${ }^{3}$, Clare Flach ${ }^{2}$ and Melanie A Abas ${ }^{2 *}$

\begin{abstract}
Background: Trafficking in women is a widespread human rights violation commonly associated with poor mental health. Yet, to date, no studies have used psychiatric diagnostic assessment to identify common forms of mental distress among survivors returning to their home country.

Methods: A longitudinal study was conducted of women aged 18 and over who returned to Moldova between December 2007 and December 2008 registered by the International Organisation for Migration as a survivor of human trafficking. Psychiatric diagnoses in women at a mean of 6 months after return (range 2-12 months) were made by a trained Moldavian psychiatrist using the Structured Clinical Interview for DSM-IV, and compared with diagnoses recorded in the same women within 5 days of return. We described the socio-demographic characteristics of the women in the sample including both pre and post-trafficking information. We then described the distribution of mental health diagnoses recorded during the crisis intervention phase (1-5 days after return) and the re-integration phase (2-12 months after return). We compared diagnoses at the patient level between the two time points by tabulating the diagnoses and carrying out a kappa test of agreement and the Stuart-Maxwell test for marginal homogeneity (an extension of the McNemar test to kxk table).
\end{abstract}

Results: 120/176 (68\%) eligible women participated. At 2-12 months after their return, 54\% met criteria for at least one psychiatric diagnoses comprising post-traumatic stress disorder (PTSD) alone (16\%); co-morbid PTSD (20\%); other anxiety or mood disorder (18\%). $85 \%$ of women who had been diagnosed in the crisis phase with co-morbid PTSD or with another anxiety or mood disorder sustained a diagnosis of any psychiatric disorder when followed up during rehabilitation.

Conclusions: Trafficked women returning to their country of origin are likely to suffer serious psychological distress that may endure well beyond the time they return. Women found to have co-morbid PTSD or other forms of anxiety and depression immediately post-return should be offered evidenced-based mental health treatment for at least the standard 12-month period of rehabilitation.

\section{Background}

Human trafficking is a human rights violation and modern form of slavery that occurs in and between most countries around the world. Trafficking in persons involves the movement of individuals by means of threat, force, coercion, or deception, for the purposes of exploitation or abuse [1]. The most commonly

\footnotetext{
* Correspondence: melanie.abas@kcl.ac.uk

${ }^{2}$ Institute of Psychiatry, King's College London, London, UK

Full list of author information is available at the end of the article
}

recognized form of human trafficking has been the sale of women and girls for sexual exploitation, but women, men and children are trafficked for various forms of labour, such as farming, manufacturing and begging [2]. Several countries in Eastern Europe, including Moldova, are well-known for high numbers of women who are trafficked for forced sex work [3]. Trafficked persons are frequently subjected to high levels of violence and abuse and at risk for symptoms of post-traumatic stress disorder (PTSD), depression and anxiety [4].
C Biomed Central

(c) 2011 Ostrovschi et al; licensee BioMed Central Ltd. This is an Open Access article distributed under the terms of the Creative Commons Attribution License (http://creativecommons.org/licenses/by/2.0), which permits unrestricted use, distribution, and reproduction in any medium, provided the original work is properly cited. 
For survivors of trafficking, there are a growing number of centers around the world that offer post-trafficking care. Support services often include activities to address the mental health needs of individuals. Yet, while there are international calls for better psychological support, [5] there remains limited clinical evidence on the mental health needs of trafficking survivors. In one of the few studies exploring the mental health symptoms of women in post-trafficking assistance centers in Europe, findings based on the Brief Symptom Inventory [6] and the Harvard Trauma Questionnaire [7] indicate that within 0-14 days of entering care, the majority of women reported high symptom levels of PTSD, depression and anxiety [8]. Importantly, no studies to date have employed clinician-administered diagnostic assessment either to describe primary or comorbid conditions. Notably, research among other groups suggests that co-morbidity in PTSD is common and may adversely affect prognosis [9].

According to conceptualization of the five stages of the trafficking process (pre-departure; travel and transit; destination; detention, deportation and criminal evidence; and integration and re-integration), [10] women will have different needs at different stages. This study focused on the last of these phases, re-integration, and women returning home. For the purposes of care and assistance the 'reintegration' phase may be divided into the 'crisis intervention' period, when urgent needs are met and support is aimed at safety and stabilization, and the 'rehabilitation' period, when support is aimed at longer-term recovery, rehabilitation and participation. This study aimed to: 1) describe women's mental health status, specifically psychiatric disorders, during the reintegration phase; and 2) explore changes in women's psychological symptoms over time, comparing diagnoses two to twelve months after their return, with earlier diagnoses made within five days of their return to Moldova.

\section{Methods}

\section{Setting}

The study took place in the Republic of Moldova in collaboration with the International Organization for Migration (IOM) in the Center for Assistance and Protection for Victims and Potential Victims of Trafficking in Human Beings. At the time of the study, IOM, as part of their Assistance, Prevention and Protection Programme, provided travel and reintegration assistance to individuals who chose to return or who were unable to remain in the country of destination http://www.iom. $\mathrm{md} /$ index.php/en/programs/counter-trafficking/assistance-a-protection-programme. Trafficked women in this study may have initially come into contact with IOM in destination settings or may have been referred to IOM in Moldova by a range of sources in destination countries, including police, immigration services, lawyers, health services and governmental and non-governmental anti-trafficking and support organizations.

\section{Profile of Re-integration Support System for Survivors of Trafficking}

As part of their Assistance and Protection Programme (APP), IOM meets returning women who have been referred into their care at their port of entry. Between 2000 and 2008, IOM assisted 2340 women returned from a trafficking experience outside Moldova. IOM's support package for trafficked persons in Moldova is led by specially trained social workers, supported by an experienced psychologist (LG). Assistance generally consists of crisis intervention care, including a medical, psychological, legal and social needs assessment, and residential care of up to 1 month, which can be extended. This is followed by a 12-month communitybased rehabilitation program, which often includes social assistance and vocational training. Approximately $80 \%$ of returning women accept the acute crisis intervention and/or the rehabilitation program. Mental health interventions include counseling, cognitive-behavioural therapy, antidepressant drug treatment, alcohol detoxification services and treatment for substance abuse and dependence. During rehabilitation, on-going antidepressant treatment relies on women being willing to attend a psychiatric hospital out-patient clinic.

\section{Sampling}

We sampled consecutive women who registered with IOM between December 2007 and October 2008 and had participated in a crisis intervention psychiatric assessment within 5 days of registering. We approached them between February 2008 and December 2008, at least two months after their registration.

\section{Recruitment}

Women survivors of trafficking were approached by an IOM social worker two to twelve months after return, either face to face or by phone, generally during their monthly follow-up appointment in the rehabilitation programme. Women were informed of the study aims, subject matter and the voluntary nature of participation was emphasised. Women who gave permission to be approached by the research team and who consented to be interviewed were interviewed at the Rehabilitation Centre or at another place of their choosing. We followed the World Health Organization Ethical and Safety Recommendations for Interviewing Trafficked Women [11]. The process complied with the IOM Data Protection Principles [12]. Ethical approval was obtained from Kings College Research Ethics Committee (CREC/07/08-56) and from N. 
Testemitanu State Medical and Pharmaceutical University Institutional Review Board.

\section{Inclusion criteria}

Women were included if they were aged 18 or over, originally resident in Moldova, had returned to Moldova in the past 2-12 months following a trafficking experience outside of Moldova, registered with IOM in Moldova as a survivor of trafficking and participated in the crisisintervention assessment (described above) 2-12 months prior. IOM defined all survivors of trafficking according to UN Protocol to Prevent, Suppress and Punish Trafficking in Persons, especially Women and Children [1].

\section{Exclusion criteria}

Women were not invited to participate or were excluded if the social worker or research psychiatrist considered them to be too distressed or unwell to take part.

\section{First data collection; Crisis intervention period and the initial psychiatric assessment}

Clinical assessments of women's initial psychiatric conditions were made available to the researchers, for women who consented. These initial psychiatric assessments were conducted within two days of women's arrival at the IOM centre (and within 5 days of registering with IOM as a returning trafficked person) by a senior consultant psychiatrist $(\mathrm{MH})$, based on the International Classification of Diseases (ICD-10) [13]. A semi-structured assessment was carried out using a locally developed checklist, which included items such as, history of feelings or symptoms of emotional distress or mental health or medical problems, current and past psychiatric and medical treatment, history of illicit drug use, nicotine and alcohol use, current medication, family background and family history of illness, personal history (which included information on early development, school/work, relationships, current life circumstances and interests), premorbid personality, a mental state examination.

Socio-demographic variables were available from recorded data, which included marital status before trafficking, employment status prior to trafficking, country trafficked to; age on return from trafficking. IOM provided restricted access to limited data in anonymised aggregated form on women who did not take part in order to enable broad comparisons to be made between participants and non-participants. The process fulfilled to the IOM Data Protection Principles [14].

\section{Second data collection - rehabilitation period psychiatric assessment}

Participants were interviewed by a Moldovan psychiatrist using the operational criteria of the DSM-IV two to twelve months after having returned to Moldova. This timeframe was selected based on staff's assessment that by this time, women's urgent needs had been met, and they were generally beginning to adjust and resettle and 12 months was the normal maximum period of support provided by the Rehabilitation Centre.

We used the Romanian version of the Non-Patient version of the Structured Clinical Interview for DSM-IV Axis I Disorders [15]. The diagnoses for the rehabilitation period interviews were made by a Moldavian psychiatrist (N.O.), familiar with the operational criteria of the DSM-IV and trained in the SCID (Video course). We assessed current (last month) mental illnesses according to the Diagnostic and Statistical Manual of Mental Disorders, fourth edition [16]. We defined having a psychiatric illness as fulfilling criteria for at least one DSM-IV Axis I psychiatric disorder. We considered translating the Schedules for Clinical Assessment in Neuropsychiatry [17] in order to be able to make ICD diagnoses, but determined that this would have been prohibitively expensive and time consuming. The SCID translated version was pre-tested by two Moldavian psychiatrists trained in standardised interviews (MH, NO) and found to be understandable to the women and of good face validity.

Alcohol use was assessed with the Alcohol Use Disorders Identification Test (AUDIT) [18], a 10-item screening instrument measuring hazardous and harmful alcohol consumption which covers consumption, drinking behaviour and alcohol related problems. Total scores of 8 or more were considered as indicators of hazardous and harmful alcohol use, as well as possible alcohol dependence [19]. Substance abuse/dependence was measured using five questions based on the Diagnostic Interview Schedule about the frequency of drug use, stated dependence, inability to cut down, need for larger amounts, and withdrawal symptoms. A list of drugs used in Moldova was provided, including cannabis, amphetamines, opiates, hallucinogens, ecstasy and solvents. Those who reported the use of any of the listed substance within the previous month were regarded as having a substance abuse. Those who answered positively to one of the questions about inability to cut down need for larger amounts, and withdrawal symptoms were classified as dependent. As the method of first and second data collection approaches differed slightly, the disorders are grouped at a higher level to be comparable - see Analysis.

\section{Sample size calculation}

Data with a convenience sample of 200 trafficked women located across seven European countries and in touch with services suggests that approximately $50 \%$ of women recently returned from being trafficked may have a depressive or anxiety disorder [8]. To estimate 
this prevalence with $95 \%$ confidence intervals, $+-7.5 \%$, at $90 \%$ power, we needed a sample of 120 women.

\section{Analysis}

All analyses were carried out in Stata version 10 [20]. We described the socio-demographic characteristics of the women in the sample including both pre and posttrafficking information (See Table 1). We then described the distribution of mental health diagnoses recorded during the crisis intervention phase (1-5 days after return) and the re-integration phase (2-12 months after return. We compared diagnoses at the patient level between the two time points by tabulating the diagnoses and carrying out a kappa test of agreement and the Stuart-Maxwell test for marginal homogeneity (an extension of the McNemar test to kxk table). These will test for the level of agreement in diagnosis of the women at the two time points and for symmetry in the cross-tabulation of diagnoses to determine if there is any systematic change in diagnoses or if changes occur evenly. Since the diagnostic tools used in the two time periods were different, in order to compare between them we grouped specific conditions into four broad syndrome clusters; PTSD; anxiety disorders excluding PTSD (panic disorder, generalized anxiety disorder and somatisation disorder); mood disorders (depression and dysthymia); and substance use disorders (substance abuse, substance dependence, alcohol use and alcohol dependence). Those with a diagnosis of adjustment or acute stress disorder during the crisis intervention phase were not included in the statistical test for change in diagnosis because these time-limited diagnoses would be very unlikely to be diagnosed at the later time point and would therefore be inappropriate for comparison.

\section{Results and Discussion}

During the study period, between December 2007 and December 2008, 178 women aged 18 and over were registered with IOM and participated in crisis assessment. See Figure 1. Social workers were subsequently able to trace 150 of these women, of whom two were excluded because of on-going severe physical illness. Of the 176 eligible, nine declined to be approached by the research team, 19 declined to give informed consent after being approached by the research team, and 28 we were unable to trace. Follow-up assessments were ultimately completed for 120 of the 176 women. More than a third $(40 \%)$ of the interviews took place at the IOM Rehabilitation Center and the majority (60\%) took place at various locations chosen by the women, e.g. their home, nearest hospital or the regional social work office. The mean time for the follow-up interview was 6 months after the crisis interview with $65 \%$ of women interviewed between 3 and 8 months.
Table 1 Socio-demographic characteristics for women survivors of trafficking

\begin{tabular}{|c|c|}
\hline Age (years) & n (\%) \\
\hline $18-20$ & $21(17.5)$ \\
\hline $21-25$ & $59(49.2)$ \\
\hline $26-30$ & $14(11.7)$ \\
\hline $31-45$ & $26(21.7)$ \\
\hline \multicolumn{2}{|l|}{ Marital status before trafficking } \\
\hline Single & $82(68.3)$ \\
\hline Married/Co-habiting & $14(11.6)$ \\
\hline Separated/Divorced/widowed & $24(19.9)$ \\
\hline \multicolumn{2}{|l|}{ Education } \\
\hline Primary education or less & $14(11.6)$ \\
\hline Lower secondary (compulsory 9 years) & $75(62.5)$ \\
\hline Upper secondary or more & $31(25.7)$ \\
\hline \multicolumn{2}{|l|}{ Employment prior to trafficking } \\
\hline Unemployed & $82(68.2)$ \\
\hline Unqualified work & $25(20.8)$ \\
\hline Student/vocational training & $7(5.8)$ \\
\hline Qualified work & $6(5)$ \\
\hline \multicolumn{2}{|l|}{ Family contact post-trafficking } \\
\hline One/both parents alive remain in contact & 91 (75.6) \\
\hline One/both parents alive none in contact & $24(19.8)$ \\
\hline Both deceased & $5(4.1)$ \\
\hline \multicolumn{2}{|l|}{ Current Residency } \\
\hline Rural & $81(67.5)$ \\
\hline Urban & $39(32.5)$ \\
\hline \multicolumn{2}{|l|}{ Country trafficked to } \\
\hline Turkey & 47(39.7) \\
\hline Russia & $33(27.5)$ \\
\hline EU countries & $14(11.6)$ \\
\hline Other (e.g. Kosovo, Albania) & $26(21.2)$ \\
\hline \multicolumn{2}{|l|}{ Employment post-trafficking } \\
\hline Unemployed & 44 (36.6) \\
\hline Unqualified work & $37(30.8)$ \\
\hline Student/vocational training & $25(20.8)$ \\
\hline Qualified work & $14(11.6)$ \\
\hline \multicolumn{2}{|l|}{ Confidant prior to trafficking } \\
\hline Yes & $51(42.5)$ \\
\hline No & $69(57.5)$ \\
\hline \multicolumn{2}{|l|}{ Confidant post-trafficking } \\
\hline Yes & $39(32.5)$ \\
\hline No & $71(67.5)$ \\
\hline \multicolumn{2}{|l|}{ Time period in trafficking situation (months) } \\
\hline $1-3$ months & $11(9.2)$ \\
\hline 4-6 months & $28(23.3)$ \\
\hline 7-12 months & $48(40.0)$ \\
\hline 13-24 months & $30(25.0)$ \\
\hline More than 24 months & $3(2.5)$ \\
\hline
\end{tabular}




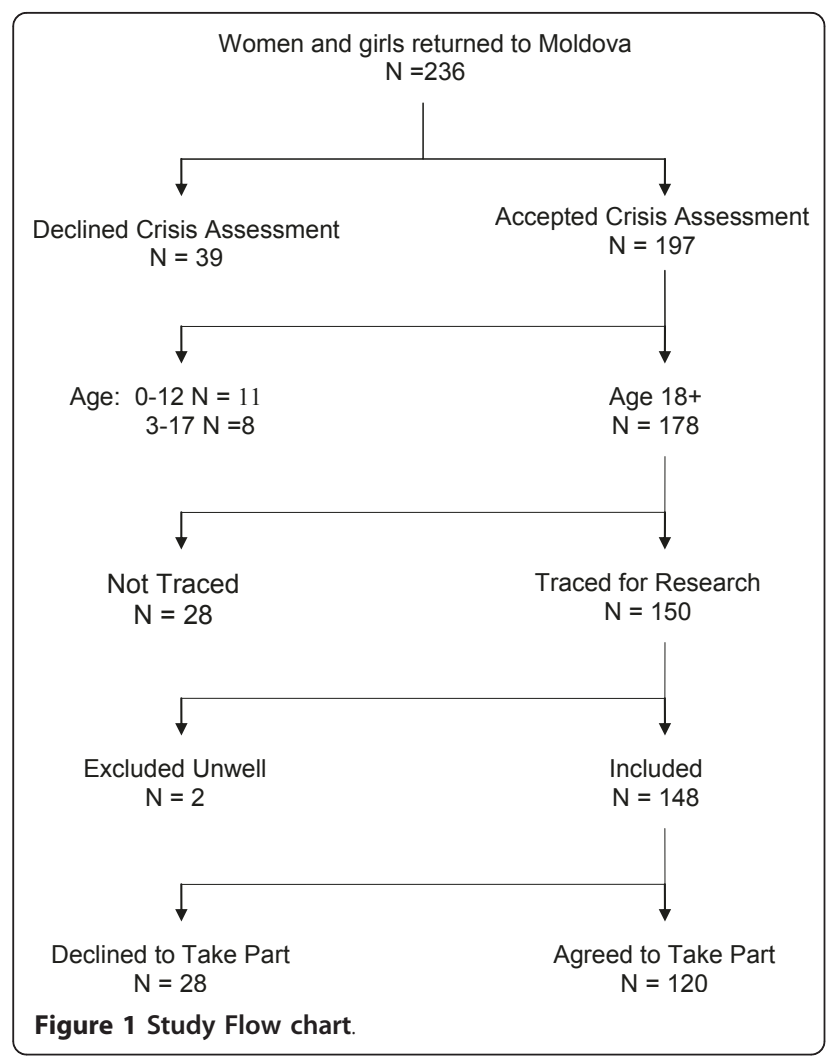

Based on the limited demographic data available to compare participants and non-participants, very little difference was observed. For example, the mean age of non-participants is 24 years-old, versus 25 for participants, $10.0 \%$ of non-participants had primary education or less compared to $11.6 \%$ of participants; and $67.1 \%$ of non-participants were single before being trafficked versus $68.3 \%$ of participants.

Characteristics of women returned after being trafficked As shown in Table 1, most women were single before being trafficked and most had completed compulsory lower secondary education (nine years), although 12\% had only attended primary school. The mean age for the sample at return was 25 years and nearly one fifth was younger than 21. Forty-seven percent of women had at least a child. Before being trafficked, $68 \%$ had been unemployed, however, this decreased to $37 \%$ post-trafficking, mostly due to opportunities for study or training organized through the IOM rehabilitation program. For $68 \%$, the trafficking situation lasted for more than six months. Since return, a fifth were not in contact with either of their parents, and less than a third of women reported having someone in whom they thought they could confide.. Most were living rurally after return.
Total prevalence of psychiatric illnesses 1-5 days after return and 2-12 months after return

Table 2 shows the total prevalence of all psychiatric illnesses, allowing for the possibility that the total number of diagnoses may be more than the number of women. In the crisis intervention period, the most common diagnoses were anxiety disorders (especially PTSD, diagnosed in $48 \%$ of women), mood disorders, adjustment

Table 2 Total Prevalence of psychiatric diagnoses in 120 Moldavian women returned to Moldova after being trafficked

\begin{tabular}{|c|c|c|}
\hline Disorder & $\begin{array}{l}\text { Psychiatric illness at } \\
\text { crisis intervention } \\
\text { phase } \\
\text { ( } 1-5 \text { days after return) }\end{array}$ & $\begin{array}{l}\text { Psychiatric illness at } \\
\text { re-integration phase } \\
\text { ( } 2-12 \text { months after } \\
\text { return) }\end{array}$ \\
\hline & $\mathrm{N}$ of diagnoses/\% & $\mathrm{N}$ of diagnoses/\% \\
\hline \multicolumn{3}{|l|}{ Anxiety disorders } \\
\hline $\begin{array}{c}\text { Posttraumatic stress } \\
\text { disorder }\end{array}$ & $58(48.3)$ & $43(35.8)$ \\
\hline Panic disorder & $4(3.3)$ & $5(4.1)$ \\
\hline $\begin{array}{c}\text { Generalized anxiety } \\
\text { disorder }\end{array}$ & $4(3.3)$ & $8(6.6)$ \\
\hline $\begin{array}{c}\text { Somatisation } \\
\text { disorder }\end{array}$ & $3(2.5)$ & $0(0)$ \\
\hline $\begin{array}{l}\text { Any anxiety } \\
\text { disorder }\end{array}$ & $69(57.5)$ & $56(44.2)$ \\
\hline \multicolumn{3}{|l|}{ Mood disorders } \\
\hline Major depression & $4(3.3)$ & $24(16.7)$ \\
\hline Dysthymia & $4(3.3)$ & $5(4.1)$ \\
\hline Any mood disorder & $8(6.6)$ & $29(24.1)$ \\
\hline $\begin{array}{l}\text { Adjustment } \\
\text { disorder }\end{array}$ & $16(13.3)$ & $0(0)$ \\
\hline $\begin{array}{l}\text { Acute stress } \\
\text { reaction }\end{array}$ & $12(10)$ & $0(0)$ \\
\hline \multicolumn{3}{|l|}{$\begin{array}{l}\text { Substance use } \\
\text { disorders }\end{array}$} \\
\hline $\begin{array}{l}\text { Alcohol harmful } \\
\text { use }^{\mathrm{a}_{\text {, }}} \text { or abuse }\end{array}$ & $5^{a}(4.2)$ & $10^{\mathrm{b}}(8.3)$ \\
\hline $\begin{array}{c}\text { Alcohol } \\
\text { dependence }\end{array}$ & $8(7)$ & $5(4.2)$ \\
\hline $\begin{array}{l}\text { Substance harmful } \\
\text { use a/abuse b }\end{array}$ & $4(3.3)$ & $5(4.2$ \\
\hline $\begin{array}{l}\text { Substance } \\
\text { dependence }\end{array}$ & $7(5.8)$ & $4(3.3)$ \\
\hline $\begin{array}{l}\text { Any alcohol or } \\
\text { substance use } \\
\text { disorder }\end{array}$ & $24(18.3)$ & $24(18.3)$ \\
\hline \multicolumn{3}{|l|}{ Psychosis } \\
\hline $\begin{array}{c}\text { Paranoid } \\
\text { Schizophrenia }\end{array}$ & $2(1.6)$ & $0(0)$ \\
\hline $\begin{array}{l}\text { Total number of } \\
\text { diagnoses }\end{array}$ & $131(110)$ & 99 (82.5) \\
\hline
\end{tabular}


and acute stress disorders and substance use disorders. Two to twelve months later during the rehabilitation period, the most common diagnoses were PTSD, mood disorder or harmful alcohol use.

\section{Diagnostic profile for individual women 1-5 days after return and 2-12 months after return}

Table 3 shows the principal single or co-morbid diagnosis for each woman. It shows that the level of co-morbidity is high in the sample at both time periods. During the rehabilitation period, $16 \%$ of women had 'pure' PTSD, while $20 \%$ had PTSD plus at least one secondary diagnosis. In more detail, (not shown in the table), 7\% of women at rehabilitation had PTSD co-morbid with depression or dysthymia, 3\% of women had PTSD comorbid with another anxiety disorder, 5\% had PTSD comorbid with substance misuse (alcohol or drug misuse), and $6 \%$ had PTSD co-morbid with both substance misuse and a mood or other anxiety disorder.

\section{Course and outcome of psychiatric illness}

As shown in Table 4, of those women having co-morbid PTSD or another anxiety or mood disorder at the early crisis intervention phase, $85 \%$ had a psychiatric illness diagnosed later, during rehabilitation. However, for those with pure PTSD or with adjustment or acute stress disorder only 1-5 days after return, only $40 \%$ had a diagnosable psychiatric illness at rehabilitation. The

Table 3 Diagnostic profile (principal single or co-morbid psychiatric diagnosis) for 120 Moldavian women returned to Moldova after being trafficked

\begin{tabular}{|c|c|c|}
\hline & $\begin{array}{l}\text { Psychiatric illness } \\
\text { at crisis } \\
\text { intervention phase } \\
\text { (1-5 days after } \\
\text { return) (ICD-10) }\end{array}$ & $\begin{array}{l}\text { Psychiatric illness } \\
\text { at re-integration } \\
\text { phase } \\
\text { (2-12 months } \\
\text { after return) } \\
\text { (DSM-IV) }\end{array}$ \\
\hline & $\mathrm{N}$ of women, $\%$ & $\mathrm{~N}$ of women, \% \\
\hline & $N=120$ & $N=120$ \\
\hline No diagnosis & $15(13)$ & $55(46)$ \\
\hline $\begin{array}{l}\text { Adjustment or acute stress } \\
\text { disorder }\end{array}$ & $28(23)$ & $0(0)$ \\
\hline Posttraumatic stress disorder & $42(35)$ & $18(15)$ \\
\hline $\begin{array}{l}\text { PTSD co-morbid with mood, } \\
\text { other anxiety, or substance } \\
\text { use disorder. }\end{array}$ & $16(13)$ & $25(21)$ \\
\hline $\begin{array}{l}\text { Mood and/or anxiety } \\
\text { disorder (not PTSD), }\end{array}$ & $11(9)$ & $12(10)$ \\
\hline $\begin{array}{l}\text { Mood or anxiety disorder co- } \\
\text { morbid with substance use } \\
\text { disorder or other (not PTSD), } \\
\text { add to above }\end{array}$ & $5(4)$ & $10(8)$ \\
\hline other & $3(3)$ & $0(0)$ \\
\hline Total with a diagnosis & $105(88)$ & $65(54)$ \\
\hline
\end{tabular}

kappa test for agreement and Stuart-Maxwell test for symmetry were run on 92 patients who did not have a diagnosis of adjustment or acute distress disorder at the crisis intervention phase. The reported diagnoses gave a kappa level of 0.27 and $41 \%$ agreement indicating low agreement between the time points. The test of homogeneity was significant ( $\mathrm{chi} 2=27.17, \mathrm{df}=5, \mathrm{p}<0.001$ ) indicating that the changes in the diagnoses of the women are not equally distributed but systematically differ between the two time points, for example the large proportion that have moved from PTSD to nodiagnosis.

\section{Discussion}

This is the first study to evaluate the mental health of trafficked women using clinician-administered psychiatric diagnostic assessment. In a consecutive cohort of women returning to Moldova who were in contact with post-trafficking care services, we found that most (88\%) women emerged from trafficking experiences with significant psychological distress, and that a portion (54\%) reached levels of clinical diagnoses for common mental disorders at 2-12 months after return. We also found that women diagnosed with co-morbid PTSD or with another anxiety or mood disorder shortly after their return were likely to continue to have poor mental health later, with $85 \%$ of such women sustaining a diagnosis of any psychiatric disorder over the following 2-12 months.

The high rate of psychiatric illness identified at the reintegration period is most likely explained by the serious nature of trauma experienced by the women during the trafficking experience. Human trafficking, especially trafficking for sexual exploitation, is renowned for the extreme forms of abuse and intimidation experienced by trafficked persons, including sexual violence, physical violence, threats of harm to themselves and their family and severely restricted movements[21]. Many of the tactics used by traffickers may be compared to those used in situations of torture [22] and are often associated with high levels of PTSD, depression and anxiety [23-26]. Other factors explaining the high rate of chronic mental disorder may include childhood adversity, personality factors, and socio-economic position ([27]. In future papers we will present analyses that explore the impact of such factors in predicting lack of mental health recovery between baseline and follow-up.

We waited a minimum of 2 months before the followup interview and a maximum of 12 months. The mean time of follow-up interview was 6 months with $65 \%$ of women interviewed between 3 and 8 months. After one month, over $90 \%$ of women have left the crisis centre and are living in the community, supported by social assistance and vocational training. It is possible that 
Table 4 Outcome of psychiatric illness for 120 Moldavian women returned to Moldova after being trafficked *

\begin{tabular}{|c|c|c|c|c|c|c|c|}
\hline \multirow[b]{2}{*}{$\begin{array}{l}\text { Psychiatric illness at crisis intervention phase } \\
\text { (1-5 days after return)* (ICD-10) }\end{array}$} & \multicolumn{5}{|c|}{ Psychiatric illness at re-integration phase (2-12 months after return)* } & \multicolumn{2}{|c|}{ (DSM-IV) } \\
\hline & $\begin{array}{l}\text { No } \\
\text { diagnosis }\end{array}$ & PTSD & $\begin{array}{l}\text { PTSD+co- } \\
\text { morbid }\end{array}$ & $\begin{array}{l}\text { Mood or anxiety } \\
\text { (not PTSD) }\end{array}$ & $\begin{array}{l}\text { Mood or anxiety +co- } \\
\text { morbid (not PTSD) }\end{array}$ & Other & Total \\
\hline No diagnosis & $9(10 \%)$ & $\begin{array}{l}1 \\
(1 \%)\end{array}$ & $0(0 \%)$ & $4(4 \%)$ & $1(1 \%)$ & $\begin{array}{l}0 \\
(0 \%)\end{array}$ & $\begin{array}{l}15 \\
(16 \%)\end{array}$ \\
\hline PTSD & $25(27 \%)$ & $\begin{array}{l}9 \\
(10 \%) \\
\end{array}$ & $8(9 \%)$ & $0(0 \%)$ & $0(0 \%)$ & $\begin{array}{l}0 \\
(0 \%)\end{array}$ & $\begin{array}{l}42 \\
(46 \%)\end{array}$ \\
\hline PTSD+co-morbid & $3(3 \%)$ & $\begin{array}{l}2 \\
(2 \%) \\
\end{array}$ & $11(12 \%)$ & $0(0 \%)$ & $0(0 \%)$ & $\begin{array}{l}0 \\
(0 \%)\end{array}$ & $\begin{array}{l}16 \\
(17 \%) \\
\end{array}$ \\
\hline Mood or anxiety (not PTSD) & $1(1 \%)$ & $\begin{array}{l}1 \\
(1 \%) \\
\end{array}$ & $2(2 \%)$ & $5(5 \%)$ & $2(2 \%)$ & $\begin{array}{l}0 \\
(0 \%)\end{array}$ & $\begin{array}{l}11 \\
(12 \%) \\
\end{array}$ \\
\hline Mood or anxiety + co-morbid (not PTSD) & $0(0 \%)$ & $\begin{array}{l}0 \\
(0 \%)\end{array}$ & $1(1 \%)$ & $0(0 \%)$ & $4(4 \%)$ & $\begin{array}{l}0 \\
(0 \%)\end{array}$ & $\begin{array}{l}5 \\
(5 \%) \\
\end{array}$ \\
\hline Other & $0(0 \%)$ & $\begin{array}{l}2 \\
(2 \%) \\
\end{array}$ & $0(0 \%)$ & $1(1 \%)$ & $0(0 \%)$ & $\begin{array}{l}0 \\
(0 \%)\end{array}$ & $\begin{array}{l}3 \\
(3 \%)\end{array}$ \\
\hline Subtotal & $38(41 \%)$ & $\begin{array}{l}15 \\
(16 \%)\end{array}$ & $22(24 \%)$ & $10(11 \%)$ & $7(8 \%)$ & $\begin{array}{l}0 \\
(0 \%)\end{array}$ & 92 \\
\hline Adjustment or acute stress disorder & $17(61 \%)$ & $\begin{array}{l}3 \\
(11 \%)\end{array}$ & 3 (11\%) & $5(18 \%)$ & $0(0 \%)$ & $\begin{array}{l}0 \\
(0 \%)\end{array}$ & 28 \\
\hline Total & $55(46 \%)$ & $\begin{array}{l}18 \\
(15 \%)\end{array}$ & 25 (21\%) & $15(13 \%)$ & $7(6 \%)$ & $\begin{array}{l}0 \\
(0 \%)\end{array}$ & 120 \\
\hline
\end{tabular}

* Percentages in table are cell percentages

women were facing a large number of stressors at this period, which could contribute to the high prevalence of mental distress. Women returning may face a myriad of difficulties after returning including family difficulties, poverty, stigma and social isolation, which pose serious challenges for their recovery. It is possible if women had been interviewed later, after 12-15 months, that we might have seen more adjustment and recovery.

We found a high rate of co-morbidity of mental disorders in re-integration phase, with the most common diagnosis being PTSD co-morbid with depression, another anxiety disorder, or with alcohol or substance use disorder. This is consistent with previous evidence suggesting that co-morbidity is common in trauma victims, especially PTSD with depression, $[28,29]$ with one review concluding that in many cases, depression and PTSD are related but independent sequelae of trauma [9].

We also found that women with a diagnosis of comorbid PTSD, compared to PTSD alone, at the early crisis intervention phase were especially likely to have a psychiatric illness 2-12 months later. Co-morbidity may partly reflect severity of the condition, which is known to be a predictor of worse outcomes [9]. Factors such as pre-departure abuse, [10] severity of trafficking abuse, length of time in the trafficking situation [21] or low levels of social support [30] may influence susceptibility to co-morbid diagnoses. It is worth recalling that less than a third of women reported feeling able to disclose to someone. Women's symptom patterns may also reflect, in part, the treatment approach, which included primarily anti-depressant drugs (which may have been inadequate), and women may have responded better if they received trauma-focussed cognitive-behavioural therapy [31] or other evidenced-based treatment, such as narrative exposure therapy [32] or eye movement desensitization and reprocessing, which are not currently available in Moldova.

\section{Limitations}

Study participants were all registered with the International Organisation for Migration (IOM) and recruited via contact with their social worker. This may mean that women with a higher level of need are represented versus if we had attempted to include women not in contact with services, biasing the sample towards overestimating mental distress. However, women not included in the study may have been those who were too distressed to identify and access services or experienced other barriers to service access such as poor education. Given the highly sensitive nature of trafficking, we did not consider it appropriate to approach women who were not contactable through a known service [11]. It is worth noting, however, that very few differences were found between women who participated versus those who did not. We were able to recruit $68 \%$ of consecutive women returning through IOM's APP program, supporting our view that our sample is reasonably representative of women participating in IOM's rehabilitation program.

It is unclear to what extent findings from this study may be generalisable to the broader population of 
trafficked women. Participants had each been referred into care and therefore may differ from the larger population of trafficked women that do not access assistance. It is likely to be only the smallest portion of women who are trafficked who receive post-trafficking support, and there is, to date, no data to compare this sample with what might be considered a 'general population of trafficked persons. For this study, we also do not have information on the differences in mental health support that women received during the rehabilitation period, so we can not account for any interventions that may have influenced women's conditions over two time periods.

A further limitation may be the different instruments used at the two time periods evaluated. The ICD-10 [13] classification was used at when women entered in the crisis phase, in line with normal practice in the centre, and DSM-IV [16] was used at the re-integration phase. Although there are at least minor differences between two classifications in almost every category of disorder, these two widely used classifications are generally found to be functionally equivalent [33] and are largely comparable[34] with a high level of concordance reported for depression, dysthymia, substance dependence and generalised anxiety disorder [33]. For PTSD, concordance between ICD and DSM is reported to range from $35 \%$ to $75 \%[33,35]$. One key difference is that ICD has a potentially lower threshold for experiencing a severely threatening event (such as being in a war zone whereas DSM requires the person to have experienced threat to their life of themselves or others to which they reacted with helplessness and/or horror. The second key difference is that ICD does not require impairment to be present whereas DSM does. The third difference is that DSM requires three symptoms of avoidance whereas ICD requires only one. Overall, the effect o the differences is that using the ICD classification is recognised to lead to an increase in prevalence estimates of PTSD, compared to if DSM criteria are used, with up to a doubling of prevalence of PTSD being reported from ICD versus DSM. Given this, our methodological differences are more likely to explain any apparent recovery by the second time period [33]. As our key finding is the extent of on-going psychiatric illness in the second time period for those with co-morbid PTSD, anxiety or depression at baseline, we can be confident that women with diagnoses at the rehabilitation phase had significant levels of mental distress and impairment, and that any difference between the two methods cannot account for women remaining or becoming more mentally unwell at follow-up. We used DSM at follow-up because a standardised interview for DSM was available in the local languages and also because DSM is well-accepted as portraying the current theoretical construct of PTSD [33,35].

\section{Implications for research}

There is currently limited knowledge about effective treatment for PTSD co-morbid with depression, especially in victims of extreme trauma. Studies are needed to evaluate treatments that show promise, such as narrative exposure therapy $[32,36]$ and trauma-focussed cognitive behaviour therapy with and without pharmacotherapy, [31] particularly in populations of trafficked persons.

\section{Conclusions}

Post-trafficking support should include mental health assessment and care both in the crisis and the rehabilitation periods. Practitioners should be especially vigilant during the crisis period for women with diagnosable anxiety or mood disorder or co-morbid PTSD, who will be at risk of on-going serious disorders. Services should also be prepared to provide or refer women to detoxification or addiction services for substance misuse problems. As states establish or refine assistance measures for trafficking survivors, including transnational and national referral mechanisms, [37] policy-makers should ensure that adequate funds are dedicated to support healthcare programs that include long-term mental health care.

Caution must be used to avoid burdening trafficked women with additional stigmatizing labels by diagnosing them with a 'disorder' given that in many cases, their psychological reactions to such life-threatening violations are normal responses to extraordinarily abnormal events. Approaches to assessment and care should prioritize confidentiality, sensitivity and empowerment to offer women the greatest hope of recovery and a better future.

\section{Acknowledgements}

We would like to acknowledge the women survivors of trafficking that participated in the study. We also would like to thank our interviewers: Carolina Trigub and Rodica Vihovanet. We also thank the Rehabilitation Center Staff social workers: Nadejda Radu, Valentina Seuta, Vera Bistritchi, Liuba Todica, the IOM Moldova local team: Martin Wiss, Stela Rotaru, Irina Todorova; and the IOM head office: Dr Jesus Sarol, Sarah Craggs, Dr Poonam Dhavan, as well as all colleagues who helped us with the project at various stages. We wish to thank Dr. Daniel David for providing the Romanian version of the SCID-I and Dr Idit Albert for advice over instruments. This research was funded by a grant from the Welcome Trust GrantGR080108

\section{Author details}

'N.Testemitanu Medical and Pharmaceutical University, Chisinau, Moldova. ${ }^{2}$ Institute of Psychiatry, King's College London, London, UK. ${ }^{3}$ International Organization for Migration, Chisinau, Republic of Moldova. ${ }^{4}$ League of Mental Health, Moldova. ${ }^{5}$ London School of Hygiene and Tropical Medicine, London, UK.

\section{Authors' contributions}

$\mathrm{NO}$ and MA were responsible for designing the study and selecting study instruments with support from MP, MH and CZ. NO, LG, VG collected the data. MA and MH supervised the study with support from MP. NO, MA, and 
CF analyzed the data. NO wrote the first draft of the paper, MA wrote the second draft. CZ, VG, MH, LG and CF contributed to subsequent drafts and all authors contributed to the final draft and approved the final draft.

\section{Competing interests}

The authors declare that they have no competing interests.

Received: 19 October 2010 Accepted: 14 April 2011

Published: 14 April 2011

\section{References}

1. United Nations: Protocol to Prevent, Suppress, and Punish Trafficking in persons, especially women and children, supplementing the United Nations Convention Against Transnational Organized Crime. In GA res 55/ 25, annex II, 55 UN GAOR Supp (No 49) at 60, UN Doc A/45/49. Volume I. New York: United Nations; 2000.

2. GAO: Human Trafficking: Better Data, Strategy, and Reporting Needed to Enhance U.S. Antitrafficking Efforts Abroad. Washington DC: United States Government Accountability Office (GAO); 2006.

3. Surtees R: Second Annual Report on Victims of Trafficking in SouthEastern Europe. 2005.

4. Caring for Trafficked Persons-Guidance for Health providers. [http:// publications.iom.int/bookstore/free/CT_Handbook.pdf].

5. Beyrer C: Is trafficking a health issue? Lancet 2004, 363(9408):564.

6. Derogatis L: BSI Brief Symptom Inventory. Administration, scoring and procedures manual Minneapolis: NCS Pearson Inc; 1993.

7. Mollica R, Caspi-Yavin Y, Lavelle J, Tor S, Yang T, Chan S, Pham T, Ryan A, de Marneffe D: Harvard Trauma Questionnaire (HTQ) Manual: Cambodian, Lao, and Vietnamese Versions Boston: Harvard Program in Refugee Trauma; 1991.

8. Zimmerman C, Hossain M, Yun K, Roche B, Morison L, Watts C: Stolen Smiles: a summary report on the physical and psychological health consequences of women and adolescents trafficked in Europe. London: London School of Hygiene \& Tropical Medicine, European Union's Daphne Programme, International Organization for Migration; 2006.

9. Brady KT, Killeen TK, Brewerton T, Lucerini S: Comorbidity of psychiatric disorders and posttraumatic stress disorder. J Clin Psychiatry 2000, 61(Suppl 7):22-32.

10. Zimmerman C, Yun K, Watts C, Shvab I, Trappolin L, Treppete M, Bimbi F, Jiraporn S, Beci L, Albrecht M, et al: The health risks and consequences of trafficking in women and adolescents. Findings from a European study. London: London School of Hygiene \& Tropical Medicine and the Daphne Programme of the European Commission; 2003.

11. Zimmerman C, Watts C: WHO Ethical and Safety Recommendations for Interviewing Trafficked Women. Geneva, Switzerland: World Health Organization; 2003.

12. International Organization for Migration: Caring for trafficked persons. Recommendations for healthcare providers. Migration IOf. Geneva: IOM; 2009.

13. World Health Organization: The ICD-10 classification of mental and behavioural disorders:Diagnostic criteria for research Geneva; 1993.

14. International Organization for Migration: Caring for Trafficked Persons. Guidance for Health Providers. International Organization for Migration (IOM). Geneva; 2009.

15. First M, Spitzer R, Gibbon M, Williams J, Ed: Structured Clinical Interview for DSM-IV-TR Axis I Disorders, Research Version, Non-patient Edition. (SCID-I/NP) New York: Biometrics Research, New York State Psychiatric Institute; 2002.

16. American Psychiatric Association: Diagnostic and statistical manual of mental disorders. Fourth Edition. Volume DSM IV Washington D.C; 1994.

17. Wing JK, Babor T, Brugha T, Burke J, Cooper JE, Giel R, Jablenski A, Regier D, Sartorius N: SCAN. Schedules for Clinical Assessment in Neuropsychiatry. Arch Gen Psychiatry 1990, 47(6):589-593.

18. Saunders JB, Aasland OG, Babor TF, de la Fuente JR, Grant M: Development of the Alcohol Use Disorders Identification Test (AUDIT): WHO Collaborative Project on Early Detection of Persons with Harmful Alcohol Consumption-II. Addiction 1993, 88(6):791-804.

19. Conigrave KM, Hall WD, Saunders JB: The AUDIT questionnaire: choosing a cut-off score. Alcohol Use Disorder Identification Test. Addiction 1995, 90(10):1349-1356.

20. StataCorp: Stata Statistical software. 10 R: College Station, TX: StataCorp LP; 2007.
21. Hossain M, Zimmerman C, Abas M, Light M, Watts C: The Relationship of Trauma to Mental Disorders Among Trafficked and Sexually Exploited Girls and Women. Am J Public Health 100(12):2442-2449.

22. Seeking Justice for Victims of Human Trafficking and Domestic Violence: Civil Remedies and Other Relief. [http://www.americanbar.org/groups/ domestic_violence/resources/resources_for_attorneys/related_areas_of_law/ trafficking.html].

23. Van Velsen C, Gorst-Unsworth C, Turner S: Survivors of torture and organized violence: Demography and diagnosis. Journal of Traumatic Stress 1996, 9(2):181-193.

24. Ramsay R, Gorst-Unsworth C, Turner S: Psychiatric morbidity in survivors of organised state violence including torture. A retrospective series. The British Journal of Psychiatry 1993, 162(1):55-59.

25. Steel Z, Silove D, Brooks R, Momartin S, Alzuhairi B, Susljik I: Impact of immigration detention and temporary protection on the mental health of refugees. Br J Psychiatry 2006, 188:58-64.

26. Steel Z, Chey T, Silove D, Marnane C, Bryant RA, van Ommeren M: Association of Torture and Other Potentially Traumatic Events With Mental Health Outcomes Among Populations Exposed to Mass Conflict and Displacement. JAMA: The Journal of the American Medical Association 2009, 302(5):537-549.

27. Abas MA, Vanderpyl J, Robinson E: Socioeconomic Deprivation and Extended Hospitalization in Severe Mental Disorder: A Two-Year FollowUp Study. Psychiatr Serv 2008, 59(3):322-325

28. Kessler RC, Sonnega A, Bromet E, Hughes M, Nelson CB: Posttraumatic stress disorder in the National Comorbidity Survey. Arch Gen Psychiatry 1995, 52(12):1048-1060.

29. Breslau N: Epidemiologic studies of trauma posttraumatic stress disorder and other psychiatric disorders. Can J Psychiatry 2002, 47(10):923-929.

30. Williams MB: A systems view of psychological trauma: Developing posttraumatic stress response paradigms. Journal of Contemporary Psychotherapy 1992, 22(2):89-105.

31. Ehlers A, Clark DM, Hackmann A, McManus F, Fennell M: Cognitive therapy for post-traumatic stress disorder: development and evaluation. Behav Res Ther 2005, 43(4):413-431.

32. Neuner F, Schauer M, Roth WT, Elbert T: A narrative exposure treatment as intervention in a refugee camp: a case report. Behavioural and Cognitive Psychotherapy 2002, 30(02):205-209.

33. Andrews $G$, Slade T, Peters L: Classification in psychiatry: ICD-10 versus DSM-IV. Br J Psychiatry 1999, 174:3-5.

34. Ibor JJL, Frances A, Jones C: Dysthymic disorder: a comparison of DSM-IV and ICD-10 and issues in differential diagnosis. Acta Psychiatrica Scandinavica 1994, 89(s383):12-18.

35. Rosner R, Powell S: Does ICD-10 Overestimate the Prevalences of PTSD? Effects of Differing Diagnostic Criteria on Estimated Rates of Posttraumatic Stress Disorder in War Zone Exposed Civilians. Trauma \& Gewalt 2009, 3:2

36. Neuner F, Schauer M, Klaschik C, Karunakara U, Elbert T: A comparison of narrative exposure therapy, supportive counseling, and psychoeducation for treating posttraumatic stress disorder in an african refugee settlement. J Consult Clin Psychol 2004, 72(4):579-587.

37. Gajic-Veljanoski O, Stewart DE: Women Trafficked Into Prostitution: Determinants, Human Rights and Health Needs. Transcultural Psychiatry 2007, 44(3):338-358.

\section{Pre-publication history}

The pre-publication history for this paper can be accessed here: http://www.biomedcentral.com/1471-2458/11/232/prepub

\section{doi:10.1186/1471-2458-11-232}

Cite this article as: Ostrovschi et al: Women in post-trafficking services in moldova: diagnostic interviews over two time periods to assess returning women's mental health. BMC Public Health 2011 11:232. 